\title{
Timelines of Philhealth Z Benefit Package for Standard Risk Coronary Artery Bypass Graft (CABG) Surgery at the University of the Philippines- Philippine General Hospital
}

\author{
Angelica V. Dela Cruz, MD, ${ }^{1}$ Dioscoro DC. Bayani II, MD, ${ }^{1}$ Eddieson M. Gonzales, MD, ${ }^{1}$ \\ Marc Denver A. Tiongson, MD, ${ }^{1}$ Arnolfo B. Tomas, MD, ${ }^{1}$ Enrique Malarin Chua II, MD, ${ }^{2}$ Miriam R. Duena, ${ }^{3}$ \\ Eric Oliver D. Sison, MD, ${ }^{1}$ Paul Ferdinand M. Reganit, MD $^{1}$ and Felix Eduardo R. Punzalan, MD ${ }^{1}$ \\ ${ }^{1}$ Division of Cardiovascular Medicine, Department of Medicine, Philippine General Hospital, University of the Philippines Manila \\ ${ }^{2}$ Department of Thoracic and Cardiovascular Surgery, Philippine General Hospital, University of the Philippines Manila \\ ${ }^{3}$ Philhealth Z Benefit Package-Billing Section, Accounting Division, Philippine General Hospital, University of the Philippines Manila
}

\begin{abstract}
Objective. The study evaluates the clinical profile of patients who underwent coronary artery bypass graft surgery (CABG) under the Philippine Health Insurance Corporation (Philhealth) Z Benefit Package (PZBP), as well as time intervals between PZBP screening, approval, and timing of surgery.

Methods. A review of medical records was done to collect data on time intervals between the screening process and Philhealth approval in CABG patients under PZBP. The clinical profile and surgical outcomes of patients were also evaluated.

Results. Sixty-three patients were included from March 2017 to December 2018. Most patients were under 6170 years old. Hypertension was the most commonly observed comorbidity. Time intervals were analyzed including identification for surgery to eligibility screening (2-217 days, median 25 days), Philhealth approval (8-266 days, median 20 days), and surgery (9-403 days, median 33 days). Postoperative atrial fibrillation was seen in $22.58 \%$. The most commonly observed complication prolonging hospitalization was pneumonia.
\end{abstract}

Conclusion. This is the first local study which evaluated the timelines of PZBP. Results may be use as basis of follow up study in the future for identification of an acceptable timeline intervals. Several modifiable factors affecting time intervals were identified for further improvement of healthcare services. The leading cause of increase length in hospitalization were HAP and AF.

Key Words: coronary artery disease, coronary bypass graft surgery, national health insurance, Z package

\section{INTRODUCTION}

Coronary artery disease $(\mathrm{CAD})$ remains a significant cause of morbidity and mortality worldwide. Based on the National Nutrition and Health Survey II (NNHeS II) in 2008, the overall prevalence of CAD among adult Filipinos aged 20 years and above is $1.3 \%$. Based on the latest report from the Department of Health, myocardial infarction

Corresponding author: Angelica V. Dela Cruz, MD Division of Cardiovascular Medicine Department of Medicine Philippine General Hospital University of the Philippines Manila Taft Avenue, Manila 1000, Philippines Email: jellydelacruz1897@yahoo.com remains the top cause of death among Filipinos. ${ }^{1}$ With exception of smoking, the prevalence of traditional CAD risk factors among Filipinos has increased since 2003. ${ }^{2}$ At present both international and local guidelines recommend revascularization by coronary artery bypass graft (CABG) surgery when indicated (Class 1 indication: $\mathrm{CABG}$ to 
improve survival is beneficial in patients with significant $>70 \%$ diameter stenosis in 3 major coronary arteries with or without the involvement of the proximal LAD artery or the proximal LAD plus 1 other major coronary artery) for the improvement of survival of high-risk patients. ${ }^{3,4}$

However, the cost of the surgery has been prohibitive especially to indigent patients. Hence, in 2012, the Philippine Health Insurance Corporation (Philhealth), the implementing body of the National Health Insurance Program (NHIP) in the Philippines, began identifying illnesses that are life or limb-threatening that require prolonged hospitalization, extremely expensive therapies, or other care that would deplete one's financial resources and classified them as Case Type Z.

In 2013, Philhealth published Case Type Z Benefit Package services and rates for members with $\mathrm{CAD}$ requiring CABG surgery through Philhealth Circular No. 0002, s. 2013. ${ }^{5}$ The University of the Philippines - Philippine General Hospital (UP-PGH) was eventually contracted as a service provider in 2014 and began screening patients for eligibility and performing $C A B G$ surgeries under the Philhealth $Z$ Benefit Package (PZBP) in March 2017.

Currently, the UP-PGH is receiving a large number of referrals nationwide due to the increasing number of patients with $\mathrm{CAD}$ requiring $\mathrm{CABG}$ under $\mathrm{PZBP}$. Hence, it is prudent to review the patient's clinical profile, the screening process, the outcomes of screening, and the performance of surgery to gauge how effective the UP-PGH as a service provider and to have insight on possible areas of improvement.

We primarily determined the timeline of PZBP CABG surgery in $\mathrm{PGH}$ including the average time intervals between identification of the need for CABG, eligibility screening approval by the screening panel, and approval by the Philhealth office and the actual performance of surgery. Moreover, we described the clinical profile, indication, and estimated preoperative risk of CAD patients screened for eligibility, their screening outcomes, and the common reasons for screening disapproval as well as a disposition for those patients who were disapproved. We also described the surgical outcomes of the patient who underwent surgery.

To date, this is the first study that described the implementation of the PZBP CABG surgery in UP-PGH. Analysis of time lag between processes and identification of areas for improvement will hasten the service provision by the hospital. It may help the physicians in fast identification of eligible patients by looking to clinical and diagnostic profiles and may improve the utilization of the PZBP. Gathered data on the common reasons for non-eligibility will eventually help in making recommendations to expand the program. Finally, knowledge of patient outcomes will provide a gauge of how effective UP-PGH is as a service provider.

\section{MATERIALS AND METHODS}

This is a retrospective review of preadmission evaluation forms and charts of patients in UP-PGH from March 2017 to December 2018. The UP-PGH is a tertiary hospital and national referral center that receives a large volume of patients whether cardiac and non-cardiac cases from different hospitals nationwide. Aside from the PZBP CABG census since 2017, there is no current study and data regarding the incidence and outcomes of coronary artery disease among patients in UP-PGH.

The protocol was approved by the University of the Philippines Manila Research Ethics Board (UPMREB) Panel. There were no direct benefits to the patients and management was not affected in this study. To avoid selection bias, a review of medical records of all patients referred for PZBP CABG was done using the Preadmission Screening Logbook where all the names, diagnoses, and plans of management of referred patients were logged in. Preadmission Evaluation Forms of identified patients were retrieved from the Philhealth section and in-patient hospital records were reviewed. Data were recorded using a standardized data collection form.

All adult patients aged 19 years old and above who were diagnosed with $\mathrm{CAD}$ by coronary angiography with class 1 indication for revascularization by $\mathrm{CABG}$ surgery based on the ACC/AHA 2011 guidelines were included in the study. Class I recommendation for CABG includes (1) to improve survival in patients with significant $(>70 \%)$ stenoses in 3 major coronary arteries with or without the involvement of the proximal left anterior descending (LAD) artery or in the proximal LAD plus 1 other major coronary artery (Level of Evidence: $B$ ) and (2) CABG or PCI to improve symptoms in patients with 1 or more significant (>70\%) coronary artery stenosis amenable to revascularization and unacceptable angina despite GDMT (Level of Evidence: $A$.) On the other hand, CABG in patients with significant $(>70 \%$ diameter) stenoses in 2 major coronary arteries with severe or extensive myocardial ischemia (eg, high-risk criteria on stress testing, abnormal intracoronary hemodynamic evaluation, or $>20 \%$ perfusion defect by myocardial perfusion stress imaging) or target vessels supplying a large area of viable myocardium is a Class II recommendation (Level of Evidence: B). All patients included underwent screening for eligibility under the PZBP for standard risk CABG surgery. Each case was presented by the attending physician to a panel composed of at least one cardiologist and one thoracic and cardiovascular surgeon. Patients not referred for screening at the discretion of their attending physicians and patients referred for screening but did not undergo screening for any reason (e.g. death or any acute clinical event precluding CABG surgery before screening) were excluded in the study.

Patients who completed the requirements as stipulated in the Philhealth Circular No. 0002.2013 and approved by the panel were endorsed to the Philhealth Office for the processing of required documents. Patients who were conditionally approved with the recommendation before complete approval were advised and assisted to complete requirements (e.g. patient requiring clearance from 
endocrinologist before screening approval). Timelines of screening and Philhealth approval of these patients were recorded. Patients who were not qualified for PZBP CABG with the provided reason for disapproval and disposition were also noted. Patients who were approved by the screening panel and patients who were endorsed to Philhealth Office were instructed by the Philhealth personnel to provide the Philheath requirements and secure the completed medical diagnostics needed within the time frame required by the service (one fiscal year from the date of receipt of the checklist by the Philhealth Regional Office). Endorsement to Surgery Department and surgical schedule will be given once approval was granted by the Philhealth Office. Time intervals between the processes of identification of the need for $\mathrm{CABG}$ based on the coronary angiogram, eligibility screening approval by the panel, approval for PZBP by the Philhealth office, and performance of the CABG surgery were documented for analysis.

The analysis was also done for the baseline clinical data including age, sex, CAD risk factors (hypertension, diabetes, smoking history, dyslipidemia), New York Heart Association (NYHA) functional classification, Canadian Cardiovascular Society (CCS) grade for angina severity, and medications using the pre-admission form and in patients charts. The level of recommendation for CABG indication based on the 2011 AHA Guideline for Coronary Artery Bypass Graft Surgery ${ }^{6}$ was also documented. Preadmission glycosylated hemoglobin (HbA1c) and fasting blood sugar (FBS), 12 lead electrocardiogram (ECG), chest X-ray, left ventricular ejection fraction (LVEF) by echocardiography, coronary angiography result with some and specific diseased coronary artery were also reviewed and recorded. Perioperative mortality risk estimate (in percent) by Euroscore II or Society of Thoracic Surgeons CABG Composite Score was also included.

Surgical outcomes of those who underwent CABG surgery under PZBP were reviewed whether discharged within the prescribed period based on the CABG Pathway (with the perioperative, operative, and post-surgical care, completing 9 days of hospitalization), whether they underwent CABG but developed perioperative complications resulting in prolonged hospitalization and whether the patient died postoperatively (Figure 1).

Data gathered from standardized data collection forms were encoded and tallied in SPSS version 10 for Windows. Clinical profile, distribution of subjects, screening outcomes were expressed in percentages. Laboratory data, risk estimates, and time intervals were expressed in means of standard deviations. Time intervals were expressed in the median to determine the approximate average of a collected skewed data.

\section{RESULTS}

All 63 patients screened for $\mathrm{CABG}$ under PZBP were included in the study.

Table 1 shows the baseline clinical profile of CAD patients who were referred for eligibility screening. Most patients were 61-70 years old. Hypertension (92\%) was the most commonly observed comorbidity of CAD. The majority of patients screened (98.4\%) had significant 3-vessel $\mathrm{CAD}$ and only 1 had 2-vessel CAD. Echocardiographic

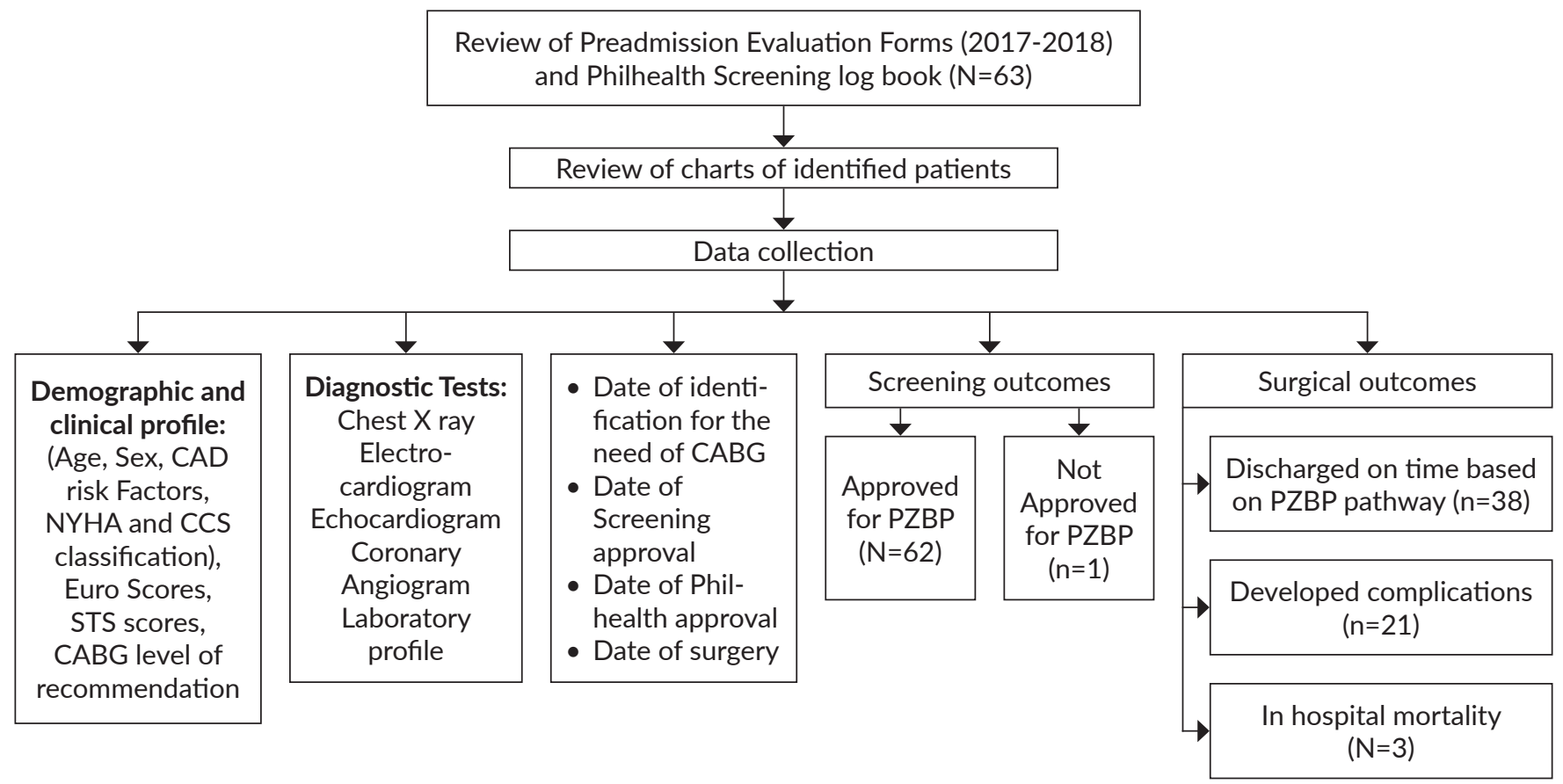

Figure 1. Research methodology. 
data showed LVEF of 29-79\% (mean $55.20 \pm 10.01$ and a median of 57\%). Most patients have preserved left ventricular ejection fraction. Two out of 5 patients with reduced ejection fraction (29\% and 31\%) on echocardiogram did not meet the criteria of PBZP (more than 35\%). These two patients underwent additional noninvasive diagnostic tests (myocardial perfusion scan) as advised of the PZBP screeners before approval.

Table 2 shows timelines from the identification of need for $\mathrm{CABG}$ based on coronary angiography to eligibility screening approval to Phil health Office approval, and the performance of CABG surgery. Philhealth approval had a median of 20 days after screening approval and the performance of surgery has a median of 33 days after the Philhealth approval. Twenty-nine patients (47\%) underwent CABG after 4-6 weeks of Philhealth approval.

The screening outcomes of the patient referred for PZBP showed that out of 63,1 patient had significant $(>70 \%$ stenosis) 2-vessel CAD without left main involvement (considered as a class IIB recommendation for CABG)

Table 1. Baseline clinical profile patients who were referred for eligibility screening for the PZBP for standard risk CABG surgery in UP-PGH

\begin{tabular}{|c|c|}
\hline & Frequency $(n=63)$ \\
\hline $\begin{array}{l}\text { Age (in years) } \\
\quad \leq 40 \\
41-50 \\
51-60 \\
61-70 \\
71-80 \\
\text { Mean } \pm \text { SD }=60 \pm 8\end{array}$ & $\begin{array}{c}1(1.6 \%) \\
7(11.1 \%) \\
18(28.6 \%) \\
32(50.8 \%) \\
5(7.9 \%)\end{array}$ \\
\hline $\begin{array}{l}\text { Sex } \\
\text { Male } \\
\text { Female }\end{array}$ & $\begin{array}{l}52(82.5 \%) \\
11(17.5 \%)\end{array}$ \\
\hline $\begin{array}{l}\text { CAD Risk Factors } \\
\text { Hypertension } \\
\text { Diabetes Mellitus } \\
\text { Smoking } \\
\text { Dyslipidemia } \\
\text { Obesity (BMI } \geq 30 \text { ) }\end{array}$ & $\begin{array}{c}58(92 \%) \\
30(47.6 \%) \\
23(36.5 \%) \\
30(47.5 \%) \\
8(12.6 \%)\end{array}$ \\
\hline $\begin{array}{l}\text { *NYHA FC } \\
\text { III } \\
\text { II } \\
\text { III }\end{array}$ & $\begin{array}{c}9(14.3 \%) \\
47(74.6 \%) \\
7(11.1 \%)\end{array}$ \\
\hline $\begin{array}{l}{ }^{*} \mathrm{CCS} \\
\text { II } \\
\text { III }\end{array}$ & $\begin{array}{c}12(19 \%) \\
44(69.8 \%) \\
7(11.1 \%)\end{array}$ \\
\hline $\begin{array}{l}\text { Electrocardiogram } \\
\text { Sinus rhythm } \\
\text { Left ventricular hypertrophy } \\
\text { Ischemia } \\
\text { Infarct }\end{array}$ & $\begin{array}{l}63(100 \%) \\
17(27 \%) \\
19(30 \%) \\
25(39.7 \%)\end{array}$ \\
\hline $\begin{array}{l}\text { Coronary Angiography: No of diseased vessel } \\
2 \\
3\end{array}$ & $\begin{array}{c}1(1.58 \%) \\
62(98.4 \%)\end{array}$ \\
\hline $\begin{array}{l}\text { Vessel involved } \\
\text { Left main coronary artery } \\
\text { Left anterior descending artery } \\
\text { Left circumflex artery } \\
\text { Right coronary artery }\end{array}$ & $\begin{array}{l}27(42.8 \%) \\
62(98.4 \%) \\
61(96.8 \%) \\
62(98.4 \%)\end{array}$ \\
\hline
\end{tabular}

hence, was not qualified for PZBP surgery. He instead underwent percutaneous transluminal angioplasty and was discharged with improved condition. Out of 62 eligible patients, 18 (29\%) were recommended to have the carotid duplex scan and referred to an endocrinologist for $\mathrm{co}^{-}$ management of diabetes, $1(1.6 \%)$ was advised to optimize medical management due to recent myocardial infarction. One patient was recommended to have a nephrologist referral due to azotemia and one was referred to a pulmonologist due to an incidental finding of pulmonary nodules.

Out of 62,38(61.3\%) patients who underwent CABG were discharged on time based on the CABG pathway with a total of 9 days of hospitalization. Twenty-one (33.9\%) developed complications and 3(4.8\%) of them died postoperatively. Of the three mortality, one patient developed acquired coagulopathy after multiple blood transfusions, one patient had fatal arrhythmia, and the other one patient developed hospital-acquired pneumonia and died due to sepsis. Postoperative atrial fibrillation was seen in 14 patients $(22.58 \%)$ and 2 of them developed cerebrovascular

Table 2. Timelines from the identification of need for CABG based on coronary angiography to eligibility screening approval, to Philhealth Office Approval, and the performance of CABG surgery

\begin{tabular}{cccc} 
Timelines & $\begin{array}{c}\text { Frequency } \\
(\mathbf{n = 6 2 )}\end{array}$ & $\begin{array}{c}\text { Median } \\
\text { (days) }\end{array}$ & $\begin{array}{c}\text { IQR } \\
\text { (days) }\end{array}$ \\
\hline Screening approval & 62 & 25 & $12-63$ \\
Philhealth approval & 62 & 45 & $26-95$ \\
Timing of Surgery & 62 & 58 & $29-118$ \\
\hline
\end{tabular}

Table 3. Surgical outcomes of patients who underwent CABG surgery under PZBP

\begin{tabular}{lc} 
& Frequency (n=62) \\
Surgery outcome & \\
Discharged on time based on CABG pathway & $38(61.3 \%)$ \\
Developed complications & $21(33.9 \%)$ \\
In Hospital Mortality & $3(4.8 \%)$ \\
\hline Post-operative complications & \\
Atrial Fibrillation & $14(22.58 \%)$ \\
Hospital Acquired Pneumonia & $8(12.90 \%)$ \\
Post-operative atelectasis & $4(6.45 \%)$ \\
Acute Kidney Injury underwent renal & $2(3.2 \%)$ \\
$\quad$ replacement therapy & \\
Acute respiratory failure from acute & $2(3.2 \%)$ \\
pulmonary congestion & \\
Surgical site infection & $2(3.2 \%)$ \\
Cerebrovascular Disease & $2(3.2 \%)$ \\
Upper gastrointestinal bleeding & $1(1.6 \%)$ \\
\hline Mortality & $4.8 \%$ \\
Hypovolemic shock from acquired & $1(1.6 \%)$ \\
$\quad$ coagulopathy & \\
Fatal arrhythmia & $1(1.6 \%)$ \\
Sepsis & $1(1.6 \%)$ \\
\hline
\end{tabular}


disease postoperatively. Hospital-acquired pneumonia was seen in 8 patients (12.90\%) and was the most commonly observed post-operative complication that caused an increased length of hospitalization (Table 3).

\section{DISCUSSION}

\section{Baseline Clinical Characteristics}

The majority of patients were males and 61-70 years old. These results were comparable with previous unpublished local study with the same age range. Hypertension was the most commonly observed comorbidity of CAD. Hypertension and the rest of the comorbidities were previously known to be modifiable risk factors and evident in patients with coronary artery disease. ${ }^{7}$ Most patients who were screened for PZBP were under NYHA II and CCS II which were comparable with the previous study of Peric V, et al. in 2017. ${ }^{8}$ These patients were believed to have a good prognosis postoperatively.

The majority of the patients included in the study had preserved ejection fraction on echocardiogram. Two of them showed reduced ejection fraction (29\% and 31\%) who did not meet the criteria of PBZP. These two patients underwent additional non-invasive diagnostic tests (myocardial perfusion imaging) as advised by the PZBP screeners before approval. Results of Myocardial Perfusion Imaging (MPI) of both patients showed an ejection fraction of more than $35 \%$ hence eventually approved for surgery under PZBP. Eligible patients should meet the criteria of $\mathrm{PZBP}$ set by the Philippine National Health Insurance with LVEF of $>35 \%$. Patients with normal ejection fraction (EF) are believed to have good prognosis post-operatively than patients with low $\mathrm{EF}$ with a 4 -fold higher risk for morbidity and mortality.

\section{Level of recommendations for CABG and Mortality Risk Estimate}

The ACC/AHA guidelines define a heart team as a multidisciplinary team composed of an interventional cardiologist/s and cardiac surgeon/s who will jointly review the patient's clinical and coronary anatomy and discusses revascularization options whether percutaneous coronary intervention or coronary artery bypass graft surgery. In line with this, the team for PZBP strictly follows the ACCF/ AHA practice guidelines for CABG and considers the level of recommendation based on the patient's clinical profile before surgical intervention. One patient was classified under class IIa level of recommendation for CABG with a low Syntax (Synergy Between PCI with TAXUS and Cardiac Surgery) score of less than 22. The SYNTAX score is used to angiographically grade the complexity of coronary artery disease and was designed to predict the postprocedural risk associated with PCI and CABG, with the scores of $0-22$, the outcomes of both procedures were comparable. The patient underwent percutaneous coronary intervention due to this finding.
The Euroscore and STS scoring systems are used to evaluate the mortality risk of patients undergoing cardiac surgery. The EuroSCORE algorithm is a good discriminatory power to predict 30-day mortality compared with the STS risk algorithm for CABG patients. ${ }^{9}$ PZBP screening also considers the mortality risk scores of referred patients by using a scoring system. In this study, the Euro score ranges from $0.5 \%$ to $4.21 \%$ and the STS score ranges from $0.3 \%$ to $3.78 \%$, both of which are considered low risk for perioperative morbidity and mortality. An analytical study of the scoring system and surgical outcomes of PZBP patients is recommended.

\section{Time Intervals for Eligibility Screening and Philhealth Approval and Surgery}

Significant CAD and identification of whether the patient may need CABG are based on symptoms and coronary angiogram results. Screening of patients by a panel composed of cardiologists and thoracovascular surgeons for eligibility requires complete diagnostics particularly echocardiography and coronary angiography.

The length of time intervals between screening approval and Philhealth approval may depend on 3 major factors: factors related to the patient, health-care-related factors, and hospital-related factors. Factors related to patients may include a firm decision by the patient and relatives for intervention. Some patients were hesitant in giving decision right away without consulting the immediate relatives, hence, resulting in delayed follow-up and delayed planning of surgery. Follow up study with regard to knowledge and attitude in CABG surgery and decision making is recommended. Four patients (6.4\%) were unsure if they will push through the CABG, who were lost to follow up and came back after several weeks consulting again for surgery. Coronary angiography of patients that were done more than 6 months before presentation on PZBP screening conference was advised to repeat the workup due to the possibility of lesion progression over the interim months. This scenario was the main reason for the delayed screening approval and surgery of some patients as reflected in the data. Timely follow up with the attending physician with complete diagnostics necessary for screening purposes is another contributory factor in delaying the screening and Philhealth for surgery. The majority of patients took around 2 weeks in obtaining laboratory results. Delayed follow up after approval from panel screening to Philhealth office for interview and completion of requirements as well as patient's preference in the timing of admission affecting surgical schedule were also observed. In general, 5 patients (8\%) were admitted in less than 30 days post-screening and 57 patients (92\%) were admitted more than 30 days after screening approval for CABG surgery. Healthcarerelated factors possibly include delays in completion of preadmission assessment form for PZBP CABG surgery, delays in obtaining the signature from physician assigned for a month, and unavailability of Philhealth personnel for final 
Philhealth approval. Hospital related factors include limited ICU bed for post-operative admission, scarcity of equipment for surgery and unavailability of certain medications in PGH pharmacy as well as unavailability of blood in the blood bank for OR use. System-level interventions to address these concerns and systems analysis to assess the impact of these interventions are thus recommended.

At present, no published data regarding acceptable timelines in PZBP CABG surgery. In PGH, Philhealth also caters $Z$ benefit package for the other non-cardiac surgery including colon, rectal, and breast surgery but their screening and surgical timelines were not comparable to the coronary bypass graft surgery. Further improvement of healthcare and the implementation of PZBP is possible by creating detailed process flow aside from the existing clinical pathway for elective CABG. Detailed process flow must have timelines on data gathering and storage, screening process and approval, completion of necessary papers, final approval by Philhealth Regional Office, and timeline on the surgery schedule.

\section{Surgical outcomes}

The majority of patients were discharged on time. HAP was the most commonly observed complication that resulted in prolonged hospital stay which was comparable in other studies with an incidence rate of $13 \% .{ }^{10} \mathrm{~A}$ significant number of patients developed Post Operative Atrial fibrillation (POAF) and 2 of them had cerebrovascular infarctions. POAF is known to be associated with a prolonged hospital stay, ICU readmission, congestion, cerebrovascular events, and increased overall costs. With the advent of increasing CABG and continuous ECG monitoring, documented AF incidence increases to 25-40\%. ${ }^{11}$ Although our study showed a lower incidence of POAF compared to several studies, identification and timely management were necessary for further improvement of surgical outcome.

The overall in-hospital mortality was 3(4.8\%). The 3 mortalities in this study were due to hemorrhagic shock from mediastinal bleeding secondary to acquired coagulopathy, fatal arrhythmia, and sepsis from hospital-acquired pneumonia. Further studies with an association of clinical and laboratory profile with surgical outcomes of patients under PZBP is recommended to recognize the importance of risk screening and perioperative care.

\section{CONCLUSION}

This is the first local study that evaluated the timelines of PZBP in the Philippines. Several modifiable factors affecting time intervals were identified which may be of help in further improvement of healthcare services. Such factors include health care related, hospital-related and patientrelated factors.

The leading cause of increased length in hospitalization post $\mathrm{CABG}$ was $\mathrm{HAP}$ and $\mathrm{AF}$ resulting in $\mathrm{CVD}$ in some patients.
The results may be used as the basis for a follow-up study for setting an acceptable timeline interval on PZBP CABG surgery. Further study on the outcomes of PZBP CABG patients is recommended. The limitation of this study was the availability of other hospital records for extensive review.

\section{Statement of Authorship}

All authors participated in the analysis, and approved the final version submitted.

\section{Author Disclosure}

All authors declared no conflicts of interest.

\section{Funding Source}

This paper was funded by the Philippine General Hospital Research Grant (2018).

\section{REFERENCES}

1. Sy RG, Morales DD, Dans AL, Paz-Pacheco E, Punzalan FER, Abelardo NS, et al. Prevalence of Atherosclerosis-Related Risk Factors and Diseases in the Philippines. J Epidemiol. 2012; 22(5):440-7. doi: 10.2188/jea.je20110095.

2. Asuncion IL, Benegas Segarra A, Timbang TD, Sinson FA, Rebanal LMR. The 2013 Philippine health statistics. Manila: Republic of the Philippines Department of Health, Epidemiology Bureau; 2013.

3. Lazaro VL. 2014 PHA Clinical practice guidelines for the diagnosis and management of patients with coronary heart disease. ASEAN Heart J. 2016 Jan; 24:3. doi: 10.7603/s40602-016-0003-6

4. Fihn SD, Gardin JM, Abrams J, Berra K, Blankenship JC, Dallas AP, et al, The 2012 ACCF/AHA/ACP/AATS/PCNA/SCAI/STS Guideline for the diagnosis and management of patients with stable ischemic heart disease. Circulation. 2012 Dec; 126(25):e354-471. doi: 10.1161/CIR.0b013e318277d6a0.

5. Philipine Health Insurance, Inc. Z Benefit Package Rates for Coronary Artery Bypass Graft Surgery, Surgery for Tetralogy of Fallot, Surgery for Ventricular Septal Defect and Cervical Cancer. Philhealth Circuclar No. 0002, s-2013. Pasig City.

6. Mannacio VA, Mannacio L. Sex and mortality associated with coronary artery bypass graft. J Thorac Dis. 2018 Jul; 10(Suppl 18): S2157-S2159. doi: 10.21037/jtd.2018.06.149

7. Raymundo E, Ramos L, Morales D. Clinical Profiles and Outcomes of Patients Who Underwent Coronary Artery Bypass Graft Procedures at Manila Doctors Hospital from May 1, 2009 to December 31, 2015. Unpublished.

8. Peric V, Stolic R, Jovanovic A, Grbic R, Lazic B, Sovtic S, et al. Predictors of quality of life improvement after 2 years of coronary artery bypass surgery. Ann Thorac Cardiovasc Surg. 2017 Oct; 23(5):233-8. doi: 10.5761/atcs.oa.16-00293.

9. Nilsson J, Algotsson L, Höglund P, Lührs C, Brandt J. Early mortality in coronary bypass surgery: The EuroSCORE versus The Society of Thoracic Surgeons risk algorithm. Ann Thorac Surg. 2004 Apr; 77(4):1235-9. doi: 10.1016/j.athoracsur.2003.08.034.

10. Topal AE, Eren MN. Risk factors for the development of pneumonia post cardiac surgery. Cardiovasc J Afr. 2012 May; 23(4):212-5. doi: 10.5830/CVJA-2012-005.

11. Miller S, Crystal E, Garfinkle M, Lau C, Lashevsky I, Connolly SJ. Effects of magnesium on atrial fibrillation after cardiac surgery: a meta-analysis. Heart. 2005 May; 91(5):618-23. doi: 10.1136/hrt. 2004.033811. 